\title{
ATUALIZAÇÃO EM TROMBOEMBOLISMO VENOSO: PROFILAXIA EM PACIENTES CLÍNICOS - PARTE II
}

Autoria

Ana Thereza Rocha - Professora colaboradora do Serviço de Pneumologia do com-HUPES e Professora Substituta do Departamento de Medicina da Faculdade de Medicina da Bahia, Salvador, BA

Edison Ferreira de Paiva - Médico assistente do Serviço de Clínica Geral do Hospital das Clínicas da Faculdade de Medicina da Universidade de São Paulo - FMUSP e Professor Colaborador da FMUSP, São Paulo, SP

Wanderley Marques Bernardo - Doutor pela Universidade de São Paulo na área de Cirurgia Torácica, Especialização em Medicina Baseada em Evidências - MBE Centre - Oxford e Especialização no Desenvolvimento de Ensaios Randomizados pela Universidade de Oxford. Membro do Comitê Técnico do Programa Diretrizes AMB/CFM, São Paulo, SP

1) Um paciente de 72 anos, portador de insuficiência cardíaca classe funcional III, é internado por dispnéia que limita a deambulação e edema importante de membros inferiores. Ele se encontra em ritmo sinusal, com PA $=100 \times 60 \mathrm{mmHg}$. Com relação à profilaxia de tromboembolismo venoso, podermos dizer que:

a) não é necessária, pois o paciente não apresenta fibrilação atrial

b) deve ser realizada com heparina não fracionada em dose plena, pois o paciente apresenta diversos fatores de risco

c) pode ser realizada com heparina, mas as medidas mecânicas são igualmente eficazes

d) deve ser realizada com heparina em doses profiláticas altas, podendo ser utilizada heparina de baixo peso molecular

e) não deve ser realizada, pois o risco de sangramento é muito elevado após os 70 anos

2) É contraindicação absoluta à utilização de heparina profilática no paciente que interna:

a) idade $>80$ anos

b) úlcera péptica ativa

c) plaquetas inferiores a $150.000 / \mathrm{mm}^{3}$

d) INR $\geq 1,5$

e) sangramento ativo

3) Homem de 35 anos, internado para controle de miocardiopatia chagásica. PA $=100 \times 80 \mathrm{mmHg}$, estertores crepitantes em bases pulmonares, edema compressível, frio e elástico em membros inferiores, até a região sacral. Está em uso de máscara de $\mathrm{O}_{2}, 10 \mathrm{~L} / \mathrm{min}$, apresentando dispnéia leve em repouso. Tem história de trombose venosa profunda há três anos. 0 peso atual é de $88 \mathrm{Kg}$. $\mathrm{Hb}=11,7 \mathrm{~g} / \mathrm{dL}$, plaquetas $=96.000 / \mathrm{mm}^{3}$, leucócitos totais $=7.000 / \mathrm{mm}^{3}$ sem desvio a esquerda, $\mathrm{Na}=$ $133 \mathrm{mEq} / \mathrm{L}, \mathrm{K}=4,2 \mathrm{mEq} / \mathrm{L}$, uréia $=70 \mathrm{mg} / \mathrm{dL}$, creatinina $=1,8 \mathrm{mg} / \mathrm{dL}$. Considerando-se o risco de tromboembolismo venoso (TEV) deste paciente, marque a melhor opção.

a) não precisa fazer profilaxia, pois tem menos de 40 anos

b) tem uma contra-indicação relativa para profilaxia farmacológica

c) precisa fazer profilaxia somente enquanto durar sua internação

d) necessita de prescrição com doses baixas de heparina para profilaxia de TEV

e) precisa de doses endovenosas de heparina, pois o edema impede a absorção das doses subcutâneas

4) Homem de 67 anos, internado por acidente vascular cerebral isquêmico, com importante restrição motora em hemicorpo esquerdo. A tomografia de crânio, realizada 12 horas após o início do quadro, foi normal. A profilaxia de tromboembolismo venoso neste paciente:

a) pode ser iniciada imediatamente, utilizando-se doses profiláticas baixas de heparina, por exemplo, heparina não fracionada a cada 12 horas

b) não pode ser realizada com heparina, devendo-se utilizar meia elástica de compressão gradual no membro inferior acometido

c) só pode ser iniciada após $010^{\circ}$ dia de internação, desde que o paciente se mantenha estável neurologicamente

d) pode ser iniciada imediatamente, utilizando-se doses profiláticas altas de heparina, por exemplo, enoxaparina $40 \mathrm{mg}$ SC uma vez ao dia

e) só pode ser iniciada após o $7^{\circ}$ dia de internação, desde que o paciente se mantenha estável clinicamente e uma nova tomografia não demonstre transformação hemorrágica

5) Quais classes funcionais de insuficiência cardíaca são consideradas fator de risco para tromboembolismo venoso?

a) II e III

b) III e IV

c) II, III e IV

d) somente IV

e) todas 


\section{Respostas ao Cenário Clínico: Tromboembolismo venoso: profilaxia em pacientes clínicos - parte I} [PUBLICADO NA RAMB 2009; 55(2)]

1) Apresentam boa evidência na literatura de que são fatores de risco para TEV em pacientes clínicos internados, EXCETO na hipertensão arterial (Alternativa E)

2) Quando indicada, a profilaxia para tromboembolismo venoso em pacientes clínicos que internam deve ser mantida por 10 \pm 4 dias, mesmo que o paciente tenha alta hospitalar (Alternativa $\mathrm{C}$ )

3) Considerando-se a perda de mobilidade do paciente que interna, qual dos pacientes abaixo deveria ser avaliado quanto à necessidade de profilaxia de tromboembolismo venoso? Todos (Alternativa D)

i. Precisa de ajuda da enfermagem para movimentação na cama

ii. Movimenta-se sozinho na cama, precisa de ajuda para levantar e não anda

iii. Fica de pé sozinho e consegue andar com ajuda

iv. Anda sozinho até o banheiro e terraço, mas passa a maior parte do tempo deitado ou sentado

4) Qual dos esquemas abaixo apresenta doses profiláticas recomendadas na profilaxia de tromboembolismo venoso de pacientes clínicos internados? Dalteparina $\mathbf{5 . 0 0 0}$ U SC uma vez ao dia (Alternativa E)

5) De acordo com a Diretriz Brasileira para Profilaxia de Tromboembolismo Venoso em Pacientes Clínicos Internados, a partir de quantos anos a idade passa a ser um fator de risco adicional para tromboembolismo? $\mathbf{5 5}$ (Alternativa C) 